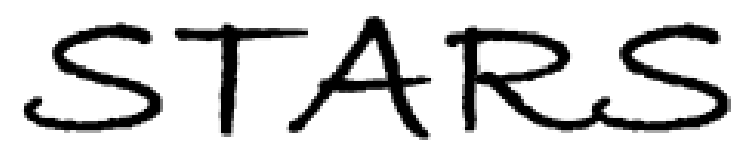

University of Central Florida

STARS

$1-1-2015$

\title{
Low-loss, submicron chalcogenide integrated photonics with chlorine plasma etching
}

Jeff Chiles

University of Central Florida

Marcin Malinowski

University of Central Florida

Ashutosh Rao

University of Central Florida

Spencer Novak

University of Central Florida

Kathleen Richardson

University of Central Florida

Find similar works at: https://stars.library.ucf.edu/facultybib2010

University of Central Florida Libraries http://library.ucf.edu

See next page for additional authors

This Article is brought to you for free and open access by the Faculty Bibliography at STARS. It has been accepted for inclusion in Faculty Bibliography 2010 s by an authorized administrator of STARS. For more information, please contactSTARS@ucf.edu.

\section{Recommended Citation}

Chiles, Jeff; Malinowski, Marcin; Rao, Ashutosh; Novak, Spencer; Richardson, Kathleen; and Fathpour, Sasan, "Low-loss, submicron chalcogenide integrated photonics with chlorine plasma etching" (2015).

Faculty Bibliography 2010s. 6468.

https://stars.library.ucf.edu/facultybib2010/6468

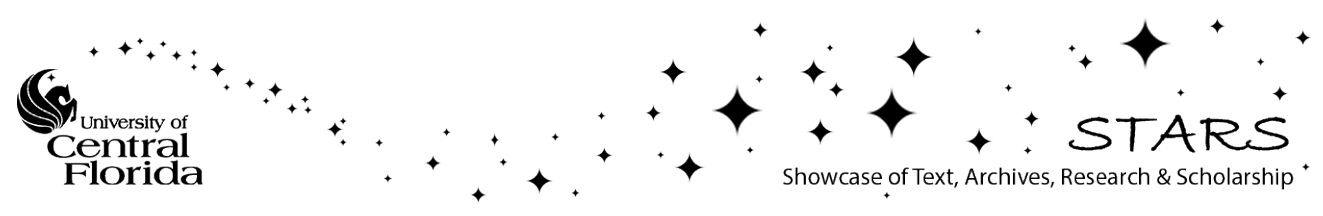




\section{Authors}

Jeff Chiles, Marcin Malinowski, Ashutosh Rao, Spencer Novak, Kathleen Richardson, and Sasan Fathpour 


\section{Low-loss, submicron chalcogenide integrated photonics with chlorine plasma etching}

Cite as: Appl. Phys. Lett. 106, 11110 (2015); https://doi.org/10.1063/1.4916207

Submitted: 28 January 2015. Accepted: 13 March 2015 . Published Online: 20 March 2015

Jeff Chiles, Marcin Malinowski, Ashutosh Rao, Spencer Novak, Kathleen Richardson, and Sasan Fathpour
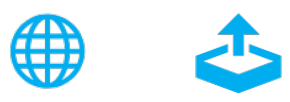

View Online

Export Citation

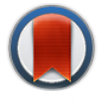

CrossMark

\section{ARTICLES YOU MAY BE INTERESTED IN}

Erratum: "Low-loss, submicron chalcogenide integrated photonics with chlorine plasma etching" [Appl. Phys. Lett. 106, 111110 (2015)]

Applied Physics Letters 109, 079903 (2016); https://doi.org/10.1063/1.4960739

Silicon-on-nitride waveguides for mid- and near-infrared integrated photonics

Applied Physics Letters 102, 121104 (2013); https://doi.org/10.1063/1.4798557

On-chip mid-infrared gas detection using chalcogenide glass waveguide

Applied Physics Letters 108, 141106 (2016); https://doi.org/10.1063/1.4945667

\section{Applied Physics Reviews} Now accepting original research 


\title{
Low-loss, submicron chalcogenide integrated photonics with chlorine plasma etching
}

\author{
Jeff Chiles, ${ }^{1}$ Marcin Malinowski, ${ }^{1}$ Ashutosh Rao, ${ }^{1}$ Spencer Novak, ${ }^{1,2}$ \\ Kathleen Richardson, ${ }^{1,2}$ and Sasan Fathpour ${ }^{1,3, a)}$ \\ ${ }^{1}$ CREOL, The College of Optics and Photonics, University of Central Florida, Orlando, Florida 32816, USA \\ ${ }^{2}$ Department of Materials Science and Engineering, COMSET, Clemson University, Clemson, \\ South Carolina 29634, USA \\ ${ }^{3}$ Department of Electrical Engineering and Computer Science, University of Central Florida, Orlando, \\ Florida 32816, USA
}

(Received 28 January 2015; accepted 13 March 2015; published online 20 March 2015)

\begin{abstract}
A chlorine plasma etching-based method for the fabrication of high-performance chalcogenidebased integrated photonics on silicon substrates is presented. By optimizing the etching conditions, chlorine plasma is employed to produce extremely low-roughness etched sidewalls on waveguides with minimal penalty to propagation loss. Using this fabrication method, microring resonators with record-high intrinsic $Q$-factors as high as 450000 and a corresponding propagation loss as low as $0.42 \mathrm{~dB} / \mathrm{cm}$ are demonstrated in submicron chalcogenide waveguides. Furthermore, the developed chlorine plasma etching process is utilized to demonstrate fiber-to-waveguide grating couplers in chalcogenide photonics with high power coupling efficiency of $37 \%$ for transverse-electric polarized modes. (C) 2015 AIP Publishing LLC. [http://dx.doi.org/10.1063/1.4916207]
\end{abstract}

Chalcogenide glasses (ChG) have been successfully utilized in a broad range of photonic platforms and devices. ${ }^{1}$ They offer fairly high refractive indices, broad transparency in the infrared region, and high optical nonlinearity. The field of integrated photonics, in particular, has benefited greatly from these properties, as chalcogenide materials can be readily deposited on conventional silicon or polymer substrates and patterned to form optical waveguides. To obtain the strongest nonlinear effects and retain compact device sizes for multi-element integrated photonic systems, submicronsized optical modes and device features are desired. There are three main techniques which have been employed for patterning submicron $\mathrm{ChG}$ waveguides, namely, liftoff patterning, nanoimprinting, and dry etching. ${ }^{2-4}$ Liftoff patterning has only demonstrated low effective propagation losses for microdisk modes (which are different from that of conventional waveguides due to the smaller interaction with sidewalls) and for larger, shallow ridge waveguides with dimensions of $1.2 \times 0.5 \mu \mathrm{m}^{2} .5$ Nanoimprinting and dry etching have produced the lowest losses for submicron optical waveguides in the range of $1.6-2 \mathrm{~dB} / \mathrm{cm}$ at $1550 \mathrm{~nm} .^{3,4}$ Although submicron features can be obtained at a low cost using nanoimprinting, the intimate physical contact required between the stamp and substrate can be hindered by particle contamination or other surface irregularities, limiting device yield.

Dry etching can produce features with steep sidewall angles, allowing very small gaps and grating periods to be achieved. In addition, it places no restrictions on the distribution or height of features that can be produced, making it suitable for a variety of applications. Although low propagation losses from 0.05 to $0.20 \mathrm{~dB} / \mathrm{cm}$ have been achieved for wider ridge waveguides with widths of $3-5 \mu \mathrm{m},{ }^{6-9}$ there is

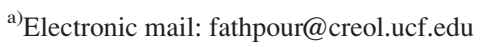

still substantial opportunity for loss reduction in submicron dry-etched chalcogenide waveguides.

In this paper, we report microring resonators with extremely low-loss submicron $\mathrm{ChG}$ waveguides, i.e., propagation loss $\sim 3$ times lower than previously reported as state of the art. The waveguides are obtained by a dry etching method, featuring compact waveguide dimensions and excellent device yield. Previously, studies of dry-etched ChG waveguides have focused mostly on fluorine-based etching recipes based on $\mathrm{SF}_{6}, \mathrm{CHF}_{3}$, or $\mathrm{CF}_{4} \cdot{ }^{10,11}$ However, no published work has explored chlorine-based plasma etching of $\mathrm{Ge}-\mathrm{Sb}-\mathrm{S} / \mathrm{Se}$ glasses for waveguiding applications. Chlorine $\left(\mathrm{Cl}_{2}\right)$ plasma is highly reactive and readily forms volatile compounds with germanium and antimony, making it a strong candidate for highly selective etching. It is shown here that $\mathrm{Cl}_{2}$ plasma etching can be used to obtain $\mathrm{ChG}$ waveguides with lower loss than those etched with $\mathrm{CHF}_{3}$, achieved in the same etching chamber. In addition, highly efficient fiber-to-waveguide grating couplers are demonstrated in ChG devices, showing the robustness of dry-etching for achieving challenging feature dimensions. By using grating couplers to couple light in and out, the need to dice and polish the chips can be avoided, saving time and improving yield. Thus, they are an important element to a complete photonic platform based on ChG materials. As demonstrated in this work, the simultaneous formation of grating couplers and ridge waveguides with one etching step further reduces the complexity of this fabrication approach.

Fabrication started with standard solvent cleaning of 100-mm diameter silicon wafers with $2 \mu \mathrm{m}$ of thermal oxide grown on the surface. Electron-beam deposition was used to produce the ChG films on the surface of the silicon dioxide. This deposition method has been previously reported, ${ }^{11}$ and is further investigated here under different deposition conditions. The deposition was performed at a rate of about $1 \mathrm{~nm} /$ $\mathrm{s}$, starting with $1 \times 1 \mathrm{~cm}^{2}$ cylindrical rods of bulk glass with 
TABLE I. Plasma etching parameters.

\begin{tabular}{lccccc}
\hline \hline Sample & Gases & $\begin{array}{c}\text { Gas flow } \\
(\mathrm{sccm})\end{array}$ & $\begin{array}{c}\text { Bias, ICP } \\
(\mathrm{W})\end{array}$ & $\begin{array}{c}\text { Selectivity } \\
(\mathrm{ChG} \text { ZZEP })\end{array}$ & $\begin{array}{c}\text { Pressure } \\
(\mathrm{mT})\end{array}$ \\
\hline $\mathrm{A}$ & $\mathrm{CHF}_{3}, \mathrm{Ar}$ & 5,30 & 50,500 & $5: 1$ & 10 \\
$\mathrm{~B}$ & $\mathrm{Cl}_{2}, \mathrm{Ar}$ & 2,40 & 50,100 & $4: 1$ & 5 \\
\hline \hline
\end{tabular}

the composition $\mathrm{Ge}_{23} \mathrm{Sb}_{7} \mathrm{~S}_{70}$. Bulk $\mathrm{Ge}_{23} \mathrm{Sb}_{7} \mathrm{~S}_{70}$ glass was fabricated by traditional melt quenching techniques. ${ }^{12} \mathrm{~A}$ film approximately 630-nm-thick was deposited on the surface of the wafer. Compositional analysis with energy dispersive X-ray spectroscopy (EDX) using a JEOL 733 Super Probe was used to compare composition of the starting bulk glass and as-deposited films. Error on the measurement was approximately \pm 1 at. $\%$. The bulk glass had a composition of Ge 22 at. \%, Sb 7 at. \%, and S 71 at. \%. The deposited film composition was Ge 22 at. \%, Sb 11 at. \%, and S 67 at. $\%$. The film composition is slightly non-stoichiometric compared to the bulk glass, which is likely an effect of the varying volatilization rates of the elements, commonly seen in ChG film deposition, and observed in previous studies of thermally evaporated $\mathrm{Ge}_{23} \mathrm{Sb}_{7} \mathrm{~S}_{70} .{ }^{13}$ The film refractive index was measured to be 2.22 at a wavelength of $1550 \mathrm{~nm}$ using the prism-coupling method. Waveguide patterning was performed using electron-beam lithography with ZEP 520A photoresist. After resist development, the line edge roughness of the pattern was reduced by reflowing it on a hot plate at $150{ }^{\circ} \mathrm{C}$ for $5 \mathrm{~min}$. The final waveguide width after reflow was found to be $750 \mathrm{~nm}$ (starting with $700 \mathrm{~nm}$ in the design).

Plasma etching was performed using a Unaxis Shuttleline inductively coupled plasma reactive ion etcher (ICP-RIE). Two different etching recipes based on $\mathrm{CHF}_{3}$ and $\mathrm{Cl}_{2}$ were investigated in order to determine the best performance (see Table I). Both samples A and B were etched by approximately $290 \mathrm{~nm}$ at a temperature of $20^{\circ} \mathrm{C}$. Sample A had a thickness of $600 \mathrm{~nm}$, and sample B was $650 \mathrm{~nm}$ thick. After etching, the samples were coated with a benzocyclobutene $(\mathrm{BCB})$ polymer cladding to protect the surfaces from contamination and to reduce scattering from the sidewalls. The curing of the polymer was performed in a nitrogen oven at a maximum temperature of $220^{\circ} \mathrm{C}$. BCB has negligible $(\sim 0.04 \mathrm{~dB} / \mathrm{cm})$ losses in the near-infrared. ${ }^{14}$ The simulated transverse-electric (TE) polarized mode intensity profile of the fabricated waveguides is shown in Fig. 1(a), with a scanning-electron-microscope (SEM) image of a cleaved waveguide facet in Fig. 1(b). The simulated waveguide from this geometry is single-mode, and its mode size is not significantly affected by the $50 \mathrm{~nm}$ thickness difference between samples A and B.
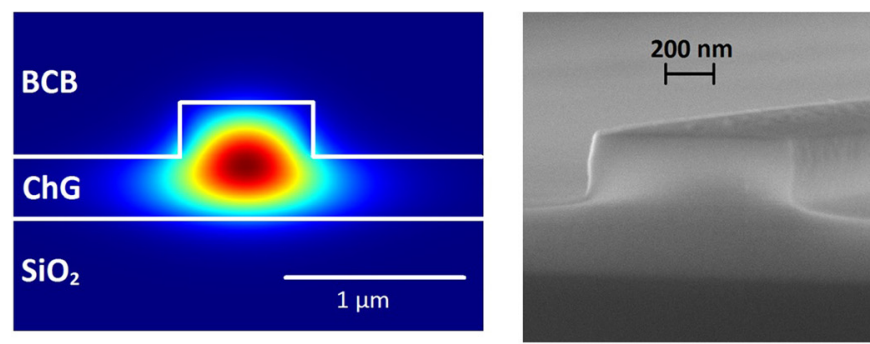

(a)

(b)
The waveguide performance was assessed by measuring the transmission spectrum through notch-filter microring resonators. Light was coupled in and out of the chips via fiberto-waveguide grating couplers and linear tapers for every resonator. A typical device is shown in Fig. 2(c). The fabricated sample contained a sweep of coupling gap distances with a fixed ring radius of $200 \mu \mathrm{m}$, allowing a clear distinction between over- and under-coupled states. The values of coupling and propagation losses were disambiguated by comparison of several waveguides with identical coupling gaps for each case. The measured coupling coefficient versus bus-to-waveguide gap distance is provided in Fig. 3(b). All of the fabricated devices on samples A and B with gap distances between 0.9 and $1.55 \mu \mathrm{m}$ were tested to obtain an estimate of the yield for the process. The measured free spectral range (FSR) was found to be $\Delta \lambda=0.842 \mathrm{~nm}$. The group index, extracted from the fitted data, was measured to be 2.30 , according to $n_{g}=\lambda_{R}^{2} / \Delta \lambda L$, where $\lambda_{R}$ is a resonant wavelength and $L$ is the circumference of the cavity.

An example transmission spectrum on resonance for one microring is given in Figs. 2(a) and 2(b), showing a good quality of fit to the simulated response, obtained from standard models. ${ }^{15}$ A histogram showing device performance from multiple resonators over two samples is given in Fig. 3(a). The high yield of the process is evident, with only one device from each sample showing abnormal behavior with higher losses. The best device on sample $\mathrm{B}$, which was $\mathrm{Cl}_{2^{-}}$ etched, showed a propagation loss of $0.42 \mathrm{~dB} / \mathrm{cm}$, corresponding to an intrinsic (unloaded) $Q$-factor of 450000 . The corresponding values on the best device on sample A are loss of $0.67 \mathrm{~dB} / \mathrm{cm}$ and an intrinsic $Q$ of 288000 . The highest attainable loaded $Q$ values are 121000 and 168000 for samples $\mathrm{A}$ and $\mathrm{B}$, respectively. The mean loss for samples $\mathrm{A}$ and $B$ are $0.89 \pm 0.13 \mathrm{~dB} / \mathrm{cm}$ and $0.54 \pm 0.07 \mathrm{~dB} / \mathrm{cm}$, respectively, corresponding to a mean intrinsic $Q$ of 215000 and 350000 . Sample B shows better process uniformity with a lower standard deviation. The standard deviation and the mean loss were obtained by statistical analysis of the ensemble of resonators, excluding only the single abnormal resonator in each sample (outliers in Fig. 3(a)).

Compared with prior reported losses of $\sim 1.6 \mathrm{~dB} / \mathrm{cm}$ for waveguides attained by $\mathrm{CHF}_{3}$-based etching at $1550 \mathrm{~nm},{ }^{4}$ sample A clearly exhibits great improvement. Nonetheless, the $\mathrm{Cl}_{2}$ plasma etching approach produces even lower etching-induced losses than $\mathrm{CHF}_{3}$ as seen in sample $\mathrm{B}$, which exhibited $\sim 3$ times lower loss than the mentioned previous reports on ChG submicron waveguides. ${ }^{3,4}$ The measured propagation loss can come from several different sources, namely, sidewall scattering from roughness on the

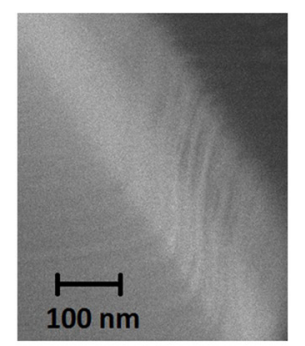

FIG. 1. (a) Simulated TE-mode intensity profile of a fabricated $\mathrm{ChG}$ waveguide. (b) Scanning-electron-microscope image of a cleaved waveguide facet. (c) Higher magnification scanning-electron microscope image showing waveguide sidewall roughness. 


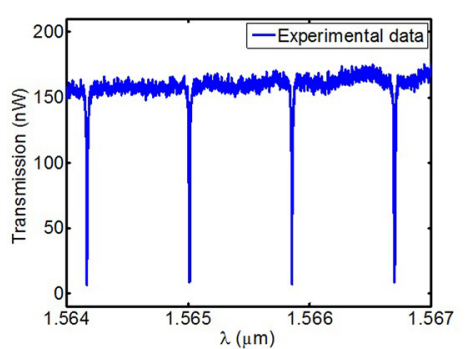

(a)

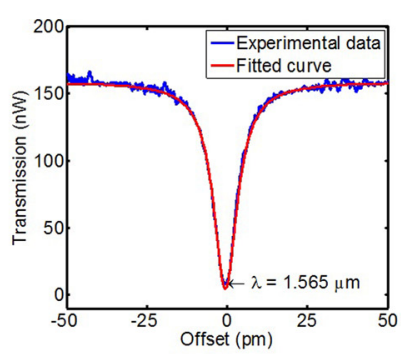

(b)

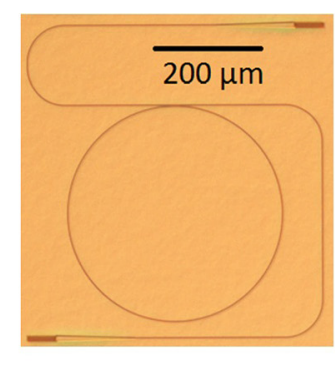

(c)

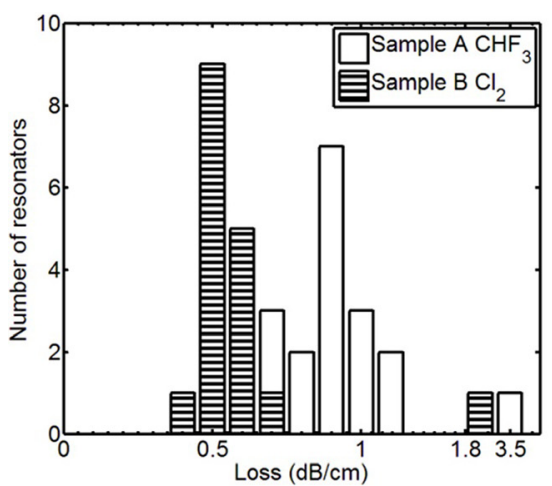

(a)

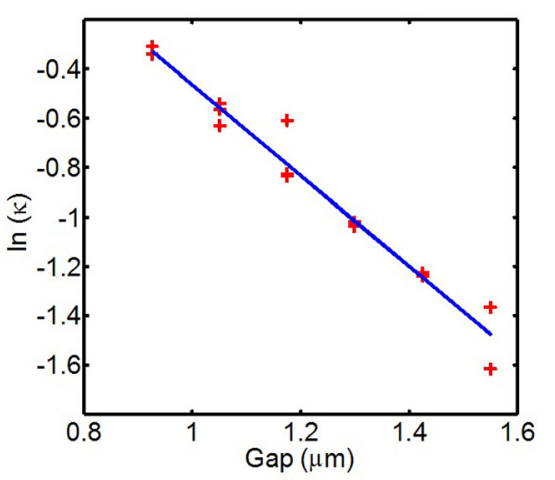

(b)
FIG. 2. (a) Transmission spectrum of a ring resonator from sample $\mathrm{B}\left(\mathrm{Cl}_{2^{-}}\right.$ etched). (b) Single-resonance zoomed view showing the quality of the fit. (c) Optical micrograph of a typical device with a $200-\mu$ m-radius microring resonator and input/output grating couplers.
FIG. 3. (a) Histogram of propagation losses for each measured resonator from the two samples; (b) Coupling coefficient of the microring resonators versus the edge-to-edge gap of the bus and ring waveguides. The red data points are measured values, and the blue line is a natural logarithmic fit to the data. waveguides, surface scattering, intrinsic material losses, and bending losses due to the measurement of a bent waveguide in a microring. Although the material loss was not characterized in this work, thermally evaporated $\mathrm{Ge}_{23} \mathrm{Sb}_{7} \mathrm{~S}_{70}$ films have been previously shown to have material losses of $\sim 0.15 \mathrm{~dB} / \mathrm{cm},{ }^{16}$ so this is used as an estimate here. COMSOL simulations show a critical bending radius of $52 \mu \mathrm{m}$ for these waveguides, and a negligible bending loss of $0.004 \mathrm{~dB} / \mathrm{cm}$ for the $200-\mu \mathrm{m}$-radius resonators employed. An atomic-force-microscope (AFM) scan of the blank film surface showed an RMS surface roughness of $0.64 \mathrm{~nm}$, which introduces negligible loss. ${ }^{5}$ Thus, sidewall scattering is expected to contribute most of the propagation loss. Analysis of an SEM image of the waveguide sidewalls (Fig. 1(c)) gave an estimated peak-to-peak sidewall line-edge roughness value of $20 \mathrm{~nm}$. This may originate in the pattern produced by the lithography, though it is reduced by the reflow process. It is also apparent from Fig. 1(c) that the sidewalls are not completely vertical; accordingly, the plasma has some small isotropic component that etches the sidewalls, producing this effect. Considering the absence of a polymerizing agent generated in the plasma, this is plausible. To further investigate the influence of sidewall roughness on the losses, microring resonators from 1000-nm-wide waveguides were also fabricated. However, no significant difference in propagation loss was observed when compared to the 750-nm-wide waveguides. Further optimization of the etching conditions and resist patterning are expected to reduce the sidewall roughness and improve performance.

Grating waveguide couplers were also demonstrated in chalcogenide integrated photonics. The grating has a fixed duty cycle of $\sim 35 \%$, a period of $1 \mu \mathrm{m}$, an etch depth of $290 \mathrm{~nm}$, and a film thickness of $630 \mathrm{~nm}$. SMF-28e single- mode fibers were aligned to the grating couplers at an incident angle of $14^{\circ}$. Index-matching fluid with a refractive index of 1.4 was used to reduce reflection losses from the grating facets. A partial sweep of the transmission through a chip with input and output gratings (limited by the laser's tuning range) is shown in Fig. 4, showing the insertion loss with respect to wavelength. The peak coupling efficiency for a single grating is measured to be $37 \% \pm 6 \%(4.3 \mathrm{~dB} \pm 0.7 \mathrm{~dB})$ from the experimental data.

A technique for fabricating low-loss chalcogenide waveguides has been presented. With chlorine and argon dry etching, record-high quality-factor submicron ridge waveguides based on $\mathrm{Ge}_{23} \mathrm{Sb}_{7} \mathrm{~S}_{70}$ were demonstrated. When compared with identical $\mathrm{CHF}_{3}$-etched waveguides, a clear improvement in waveguiding performance for $\mathrm{Cl}_{2}$-etched waveguides was

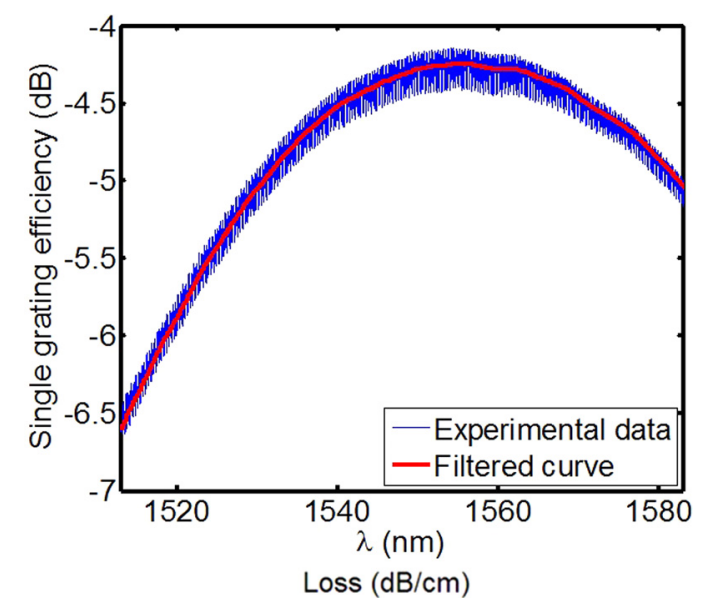

FIG. 4. Grating coupler efficiency versus wavelength. The upperwavelength measurement is limited by the tuning range of the laser. 
observed. A factor of $\sim 3$ reduction in waveguide propagation loss has been realized with the present etching method consistent with improved sidewall quality. In addition, highefficiency grating couplers with a single-grating loss of $4.3 \mathrm{~dB}$ were achieved. With enhanced apodized grating designs, even higher efficiencies should be possible. Further work is underway to extend these performance gains and utilize them in multi-element integrated optical systems.

The work was supported by the U.S. Office of Naval Research (ONR) Young Investigator Program (YIP) under the Grant No. 11296285 and the U.S. National Science Foundation under Award No. ECCS-1128208. Partial support to the co-authors (S.N. and K.R.) is acknowledged by DTRA through Contract Nos. HDTRA1-10-1-0101 and HDTRA1-13-1-0001. The authors thank Daniel Franklin for assistance with the AFM analysis.

${ }^{1}$ B. J. Eggleton, B. Luther-Davies, and K. Richardson, "Chalcogenide photonics," Nat. Photonics 5, 141-148 (2011).

${ }^{2}$ L. Li, H. Lin, S. Qiao, Y. Zou, S. Danto, K. Richardson, J. D. Musgraves, N. Lu, and J. Hu, "Integrated flexible chalcogenide glass photonic devices," Nat. Photonics 8, 643-649 (2014).

${ }^{3}$ Y. Zou, D. Zhang, H. Lin, L. Li, L. Moreel, J. Zhou, Q. Du, O. Ogbuu, S. Danto, J. D. Musgraves, K. Richardson, K. D. Dobson, R. Birkmire, and J. $\mathrm{Hu}$, "High-performance, high-index-contrast chalcogenide glass photonics on silicon and unconventional non-planar substrates," Adv. Opt. Mater. 2, 478-486 (2014).

${ }^{4}$ X. Gai, D.-Y. Choi, S. Madden, and B. Luther-Davies, "Polarization-independent chalcogenide glass nanowires with anomalous dispersion for alloptical processing," Opt. Express 20, 13513-13521 (2012).

${ }^{5}$ J. Hu, V. Tarasov, N. Carlie, N.-N. Feng, L. Petit, A. Agarwal, K. Richardson, and L. Kimerling, "Si-CMOS-compatible lift-off fabrication of low-loss planar chalcogenide waveguides," Opt. Express 15, 11798 (2007).
${ }^{6}$ W. C. Tan, M. E. Solmaz, J. Gardner, R. Atkins, and C. Madsen, "Optical characterization of a- $\mathrm{As}_{2} \mathrm{~S}_{3}$ thin films prepared by magnetron sputtering," J. Appl. Phys. 107, 033524 (2010).

${ }^{7}$ Y. Ruan, W. Li, R. Jarvis, N. Madsen, A. Rode, and B. Luther-Davies, "Fabrication and characterization of low loss rib chalcogenide waveguides made by dry etching," Opt. Express 12, 5140 (2004).

${ }^{8}$ X. Gai, T. Han, A. Prasad, S. Madden, D.-Y. Choi, R. Wang, D. Bulla, and B. Luther-Davies, "Progress in optical waveguides fabricated from chalcogenide glasses," Opt. Express 18, 26635-26646 (2010).

${ }^{9}$ S. J. Madden, D.-Y. Choi, D. A. Bulla, A. V. Rode, B. Luther-Davies, V. G. Ta'eed, M. D. Pelusi, and B. J. Eggleton, "Long, low loss etched $\mathrm{As}_{2} \mathrm{~S}_{3}$ chalcogenide waveguides for all-optical signal regeneration," Opt. Express 15, 14414 (2007).

${ }^{10}$ J. Hu, V. Tarasov, N. Carlie, L. Petit, A. Agarwal, K. Richardson, and L. Kimerling, "Exploration of waveguide fabrication from thermally evaporated Ge-Sb-S glass films," Opt. Mater. (Amsterdam) 30, 1560-1566 (2008).

${ }^{11}$ V. Nazabal, M. Cathelinaud, W. Shen, P. Nemec, F. Charpentier, H. Lhermite, M.-L. Anne, J. Capoulade, F. Grasset, A. Moreac, S. Inoue, M. Frumar, J.-L. Adam, M. Lequime, and C. Amra, "Chalcogenide coatings of $\mathrm{Ge}_{15} \mathrm{Sb}_{20} \mathrm{~S}_{65}$ and $\mathrm{Te}_{20} \mathrm{As}_{30} \mathrm{Se}_{50}$," Appl. Opt. 47, C114 (2008).

${ }^{12}$ L. Petit, N. Carlie, F. Adamietz, M. Couzi, V. Rodriguez, and K. C. Richardson, "Correlation between physical, optical and structural properties of sulfide glasses in the system Ge-Sb-S," Mater. Chem. Phys. 97, 64-70 (2006).

${ }^{13}$ J. D. Musgraves, N. Carlie, J. Hu, L. Petit, A. Agarwal, L. C. Kimerling, and K. A. Richardson, "Comparison of the optical, thermal and structural properties of $\mathrm{Ge}-\mathrm{Sb}-\mathrm{S}$ thin films deposited using thermal evaporation and pulsed laser deposition techniques," Acta Mater. 59, 5032-5039 (2011).

${ }^{14}$ C. A. Langhoff, T. Stokich, and B. Heistand, "BenzoCycloButene (BCB): A polymeric system for passive optical interconnects," Proc. SPIE 1849, 336-341 (1993).

${ }^{15}$ D. G. Rabus, Integrated Ring Resonators, Springer Series in Optical Sciences (Springer, Berlin Heidelberg, 2007), Vol. 127, p. 5.

${ }^{16}$ D. R. Scherer, J. M. Hensley, K. R. Parameswaran, B. D. Casse, V. Singh, P. T. Lin, A. Agarwal, L. C. Kimerling, J. Giammarco, J. Wilkinson, I. Luzinov, J. D. Musgraves, K. Richardson, J. Hu, C. S. Kim, W. W. Bewley, C. L. Canedy, I. Vurgaftman, J. Abell, J. R. Meyer, and M. Kim, "Characterization of mid-infrared interband cascade laser coupling to a GeSbS chalcogenide glass waveguide," in 2012 Conference on Lasers and Electro-Optics (CLEO), Physical Sciences, Inc. (2012). 